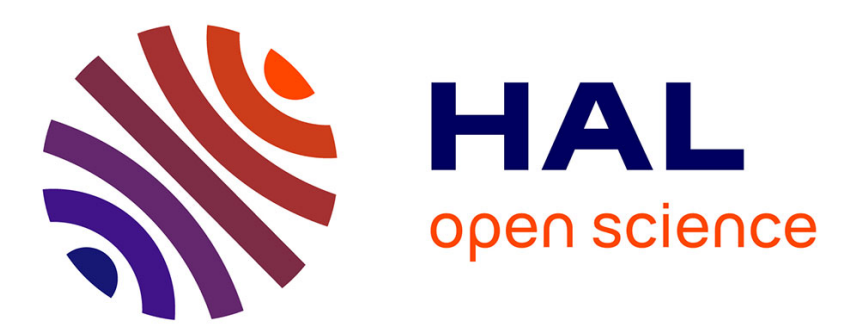

\title{
Analysis of Magnetite and related Ferrites by Means of Magnetic After-Effect-Spectra
}

\author{
F. Walz, V. Brabers, H. Kronmüller
}

\section{To cite this version:}

F. Walz, V. Brabers, H. Kronmüller. Analysis of Magnetite and related Ferrites by Means of Magnetic After-Effect-Spectra. Journal de Physique IV Proceedings, 1997, 07 (C1), pp.C1-569-C1-572. 10.1051/jp4:19971235 . jpa-00254909

\section{HAL Id: jpa-00254909 https://hal.science/jpa-00254909}

Submitted on 1 Jan 1997

HAL is a multi-disciplinary open access archive for the deposit and dissemination of scientific research documents, whether they are published or not. The documents may come from teaching and research institutions in France or abroad, or from public or private research centers.
L'archive ouverte pluridisciplinaire HAL, est destinée au dépôt et à la diffusion de documents scientifiques de niveau recherche, publiés ou non, émanant des établissements d'enseignement et de recherche français ou étrangers, des laboratoires publics ou privés. 


\title{
Analysis of Magnetite and related Ferrites by Means of Magnetic After- Effect-Spectra
}

\author{
F. Walz, V.A.M. Brabers* and H. Kronmüller \\ MPI für Metallforschung, Institut für Physik, Heisenbergstr. 1, 70569 Stuttgart, Germany \\ * Technische Universiteit Eindhoven, Postbus 513, 5600 MB Eindhoven, Netherlands
}

\begin{abstract}
The magnetic aftereffect (MAE) spectra of magnetite $\left(\mathrm{F}_{\varepsilon_{3}} \mathrm{O}_{4}\right)$ and related spinel ferrites react most sensibly on smallest deviations of the crystal stoichiometry due to intrinsic or extrinsic lattice defects. Thus, the analysis of corresponding MAE spectra represents both an effective tool for quality control and classification of these materials and, moreover, a high-sensitive instrument for the detection and identification of respective lattice defects. The efficiency of this technique is demonstrated in the following on a series of instruct.jve examples.
\end{abstract}

\section{INTRODUCTION}

Magnetite is a most interesting substance with respect to both fundamental and practical aspects [1].

i) Fundamentally, it is fascinating to study the various charge transfer mechanisms contributing to the semiconducting processes of $\mathrm{Fe}_{3} \mathrm{O}_{4}$ within typical temperature regimes, i.e. electron tunnelling $(4 \mathrm{~K}<T<35 \mathrm{~K})[2,3]$, long-range electron hopping $(50 K<T<125 K)[2,3]$ - being dramatically modified by a first-order crystal transformation from pseudo-orthorhombic to cubic symmetry at $T_{V} \simeq 125 \mathrm{~K}[1-3]$-- and vacancy-induced jumping of $F e^{2+}$ ions near $300 \mathrm{~K}$ $[3,4]$. The applicability of the MAE technique to the investigation of these various conductivity mechanisms in $\mathrm{Fe}_{3} \mathrm{O}_{4}$ is due to the fact that any electron exchange between crystallographically ordered $F e^{2+}$ and $F e^{3+}$ ions is accompanied by a corresponding local transfer of magnetic anisotropy. This anisotropy transfer being based on the residual orbital moments of $F e^{2+}\left(3 d^{6}\right)$ jons -... in contrast to the zero-momentum of $F e^{3+}\left(3 d^{5}\right)$ ions - may be expressed by the following reaction:

$$
F e^{3+}+e^{-} \rightleftarrows F e^{2+}
$$

ii) In the praxis, one is interested in designing well-defined ferrites disposing of specific, problem-orientated physical properties. Usually, this aim is achieved by systematically modifying the intrinsic properties of the basis material, here $\mathrm{Fe}_{3} \mathrm{O}_{4}$, by adjoining appropriate ionic substitutions. Evidently, for successful modelling of such specific ferrimagnetic compounds, it is a prerequisite to start with basis material of perfect quality and to observe the induced variations with highest resolution. This report is intended to give a survey on the high efficiency of the MAE spectroscopy with respect to both material control and analysis of specific, defect-induced processes in different magnetite-based ferrimagnetics. To this purpose we present and discuss the characteristic MAE spectra of (i) as-perfect mono- and polycrystalline $\mathrm{Fe}_{3} \mathrm{O}_{4}[2-4]$ and the specific modifications of these spectra after the introduction of (ii) intrinsic lattice

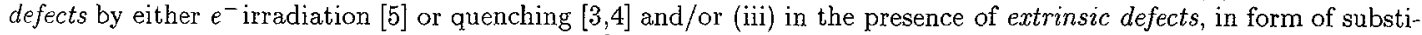
tutionally implanted ionic impurities such as $\mathrm{Mn}^{2+}, \mathrm{Ni}^{2+}, \mathrm{Ba}^{2+}, \mathrm{Ga}^{2+}$, etc... [6].

\section{EXPERIMENTAL TECHNIQUES}

\subsection{Specimen preparation}

Magnetite crystals of different type have been investigated: (i) Perfectly annealed, highly stoichiometric, molten-zone grown monocrystals of $\langle 110\rangle$ orientations; (ii) polycrystals, prepared by sintering in atmospheres of well-defined oxygen partial pressures, so as to induce well-defined concentrations of octahedral (B-site-) vacancies which, at the end of the annealing treatment, were frozen-in by rapid quenching into liquid nitrogen [2-4]; (iii) ferrimagnetic compounds, prepared -- after admixing appropriate substitutions … under similar conditions as in (ii), [6]. 


\subsection{Magnetic after-effect technique}

MAEs are observed in the temperature range $4 \mathrm{~K}<\mathrm{T}<500 \mathrm{~K}$, during time intervals of $1 \mathrm{~s}<t_{2} \leq 180 \mathrm{~s}$, using a sensitive automatic LC-oscillator technique working at frequencies near $1 \mathrm{kHz}$ [7]. The data are plotted in form of isochronal real-part differences of the complex reluctivity, $\mathrm{r}(\mathrm{t}, \mathrm{T})$ - i.e. the reciprocal susceptibility - as measured, after well-defined sample demagnetization, at $t_{1}(1 \mathrm{~s})$ and the range of ensuing times $\left(2 \mathrm{~s} \leq t_{2} \leq 180 \mathrm{~s}\right)$ :

$$
\frac{\Delta r}{r_{1}}=\frac{\Delta r\left(t_{1}, t_{2}, T\right)}{r\left(t_{1}, T\right)}=\frac{r\left(t_{2}, T\right)-r\left(t_{1}, T\right)}{r\left(t_{1}, T\right)}
$$

This type of data presentation has the inherent advantage of immediately separating multiprocess relaxations into their different constituents, by resolving them as individual peaks within the MAE spectra [8]. Such peaks, after submission to standard numerical analysis, provide us with all relevant activation data of respective atomistic processes [6-8].

\section{DISCUSSION OF MAE SPECTRA IN $\mathrm{Fe}_{3} \mathrm{O}_{4}$ - BASED SYSTEMS}

\subsection{Standard MAE spectrum of stoichiometric $\mathrm{Fe}_{3} \mathrm{O}_{4}$}

The typical spectrum of highly perfect, stoichiometric monocrystalline magnetite (Fig.1), arising from various mechanisms of electronic charge transfer, is confined to the temperature range below the Verwey transition $\left(T_{V} \simeq 125 \mathrm{~K}\right)$. In non-perfect $\mathrm{Fe}_{3} \mathrm{O}_{4}$ this low-temperature spectrum is suppressed, whereas above $T_{V}$ new relaxations may appear due to interactions with intrinsic (Fig.2,3) or extrinsic (Fig.4) lattice defects.

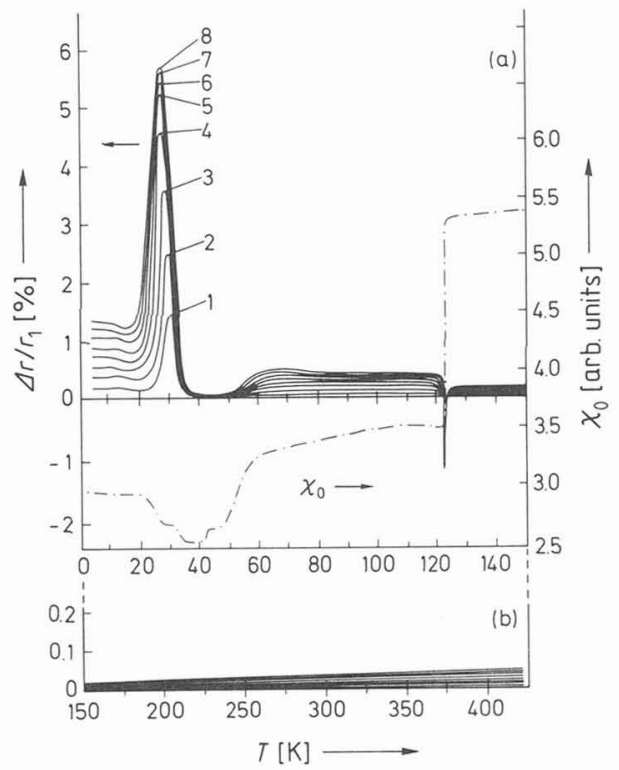

Figure 1: MAE spectrum and initial suscebtibility, $\chi_{0}$, of as-perfect $\mathrm{Fe}_{3} \mathrm{O}_{4}$. Isochronal notation is given in times, $\mathrm{t}_{2}$, elapsed after demagnetization, i.e. $\left(t_{1}=1 \mathrm{~s}\right), t_{2}=$ $1(2), 2(4), 3(8), 4(16), 5(32), 6(64), 7(128), 8(180) \mathrm{s}$.

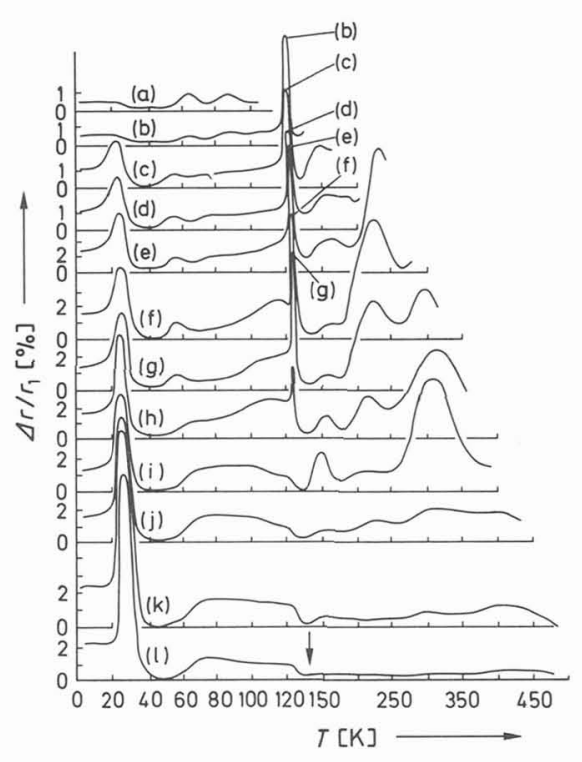

Figure 2: Anmealing sequence of an $e^{-}$-irradiated $\mathrm{Fe}_{3} \mathrm{O}_{4}$ monocrystal, like in Fig. 1 , illustrating the recovery of the spectra $\left(\mathrm{t}_{2}=180 \mathrm{~s}, \mathrm{t}_{1}=1 \mathrm{~s}\right)$ from the as-irradiated (a)

The low-temperature spectrum of stoichiometric magnetite, Fig.1, starts with a plateau-like relaxation zone of logarithmic time-dependence $(4 \mathrm{~K}<\mathrm{T}<20 \mathrm{~K}$ ) which is superimposed by a Debye-like relaxation peak near $30 \mathrm{~K}$. These processes have been associated with electron tunnelling and, concerning the $30 \mathrm{~K}$ peak, combined thermal excitation of intra-atomic electronic states [2,3]. An ensuing relaxation gap, between $35 \mathrm{~K}<\mathrm{T}<50 \mathrm{~K}$, being accompanied by a pronounced decay of the initial susceptibility, indicates freezing-in of magnetic anisotropy due to thermal destruction of the tunnelling niveaus, thereby interrupting any type of electron exchange. At elevated temperatures, extending between $50 \mathrm{~K}<\mathrm{T}<125 \mathrm{~K}$, thermally activated multi-range hopping of electrons between crystallographically ordered $\mathrm{Fe}^{2+}$ and $\mathrm{Fe}^{3+}$ ions gives rise to a further plateau-like relaxation zone of logarithmic time dependence. At the Verwey temperature, $T_{V}$. due to a first-order transition of the crystal structure from pseudo-arthorhombic to cubic, the ionically ordered low-temperature phase is destroyed. This leads to accelerated interatomic electron exchange rates which can no longer be follwed by the MAE - as is clearly reflected from the abrupt decay of the hopping plateau at $\mathrm{T}_{V}$, Fig.1. 


\subsection{MAE Spectra of intrinsically damaged $\mathrm{Fe}_{3} \mathrm{O}_{4}$}

\subsubsection{Electron-irradiated monocrystals}

In order to study the influence of simple intrinsic lattice defects, i.e. monovacancies and interstitials, on the ideal MAE spectrum (Fig.1), a monocrystal of similar type has been low-temperature $\mathrm{e}^{-}$-irradiated [5], Fig.2. Immediately after irradiation (Fig.2a,b), we find the tunnelling-plateau $(4 \mathrm{~K}<\mathrm{T}<20 \mathrm{~K})$ strongly reduced, the $30 \mathrm{~K}$ Debye peak completely suppressed, the relaxation gap $(35 \mathrm{~K}<\mathrm{T}<50 K)$ unchanged, the original hopping-plateau $(50 \mathrm{~K}<\mathrm{T}<$ $125 \mathrm{~K}$ ) suppressed and replaced, instead, by two separated Debye-type processes at $68 \mathrm{~K}$ and $90 \mathrm{~K}$ and the Verwey transition accompanied by a huge, spike-like peak near $125 \mathrm{~K}$. On annealing to about $280 \mathrm{~K}$, two new Debye-type relaxations appear near $230 \mathrm{~K}$ and $300 \mathrm{~K}$ and the gradual recovery of the low-temperature processes sets in (Fig.2c-h). This scenario may be well explained in terms of the radiation-induced lattice damage: (i) Vacancies and interstitials, like any other type of defects, destroy the periodic lattice potential and thereby interrupt the low-temperature electronic charge transfer mechanisms. (ii) The occurrence of a Debye-type relaxation near $300 \mathrm{~K}$ has been studied previously in detail and identified to result from - $\mathrm{Fe}^{2+}$ ion jump-induced - reorientations of anisotropic B-site vacancies in the spinel $[3,4,6]$. (iii) On account of the as-perfect basis material and the well-defined simple intrinsic lattice defects, it is most tentative to associate the additionally appearing $230 \mathrm{~K}$ relaxation (Fig.2e-h) - which proves to be composed of two processes at $220 \mathrm{~K}$ and $240 \mathrm{~K}$ - to reorientable interstitial configurations. (iv) This interpretation is supported by the simultaneous occurrence of the spike-like $125 \mathrm{~K}$ relaxation (Fig.2b-h) which, in preceding investigations [2-4,6], was found to be of stress-induced nature and thus may be regarded here as a sensor on interstitially induced elastic microstresses. (v) $\mathrm{It}$ is interesting to recognize the indicative roles of the $30 \mathrm{~K}$ and the $125 \mathrm{~K}$ processes within the annealing sequence: whereas the tunnelling-induced $30 \mathrm{~K}$ peak is affected by all types of lattice defects and, consequently, recovers up to its original strength with continued annealing, the stress-induced 125 $\mathrm{K}$ process reacts specifically only on interstitial interactions and disappears with the final recovery of the $230 \mathrm{~K}$ process.

\subsubsection{Vacancy-induced polycrystalline $\mathrm{Fe}_{3-\Delta} \mathrm{O}_{4}$}

The influence of $B$-site vacancies on the MAE of polycrystalline magnetite has been systematically investigated over a wide range, $10^{-5}<\Delta<10^{-1}$ [2-4]. Fig.3 illustrates the characteristic effects of already small $\left(\Delta \approx 10^{-4}\right)$ vacancy contents on the MAE spectrum of $\mathrm{Fe}_{3} \mathrm{O}_{4}$. Whereas the low-temperature tunnelling-plateau $(4 \mathrm{~K}<\mathrm{T}<20$ $\mathrm{K}$ ) appears relatively unchanged, the $30 \mathrm{~K}$ Debye peak is completely suppressed. The hopping-plateau $(50 \mathrm{~K}<\mathrm{T}$ $<125 \mathrm{~K}$ ) appears with slightly increased amplitudes, being escorted by two anomalous, spike-like peaks near 100 $\mathrm{K}$ and $125 \mathrm{~K}$ which could be identified as resulting from sinter-induced internal stresses (Sect.2.1),[2-4]. The most important vacancy-induced effect is the occurrence of a pronounced Debye-type relaxation near $300 \mathrm{~K}$ which, as mentioned above, can be unambiguously attributed to the reorientation of trigonally distorted B-site vacancies [2-4]. The relatively large width of this process is explained by a close superposition of, at least, two similar processes differing energetically by the activation enthalpy of electron hopping. In our model this difference results from two modes of vacancy reorientation: (i) by either a direct jump of a $\mathrm{Fe}^{2+}$ ion or - with somewhat increased enthalpy - (ii) by a $\mathrm{Fe}^{3+}$ ion which, prior to jumping, has to pick up a hopping electron. The similarity of the relaxations occurring in $\mathrm{e}^{-}$-irradiated monocrystalline and in vacancy-doped polycrystalline magnetite suggests to explain both effects within the same model and to obtain thereby the key for a consistent interpretation of all radiation-induced $\mathrm{MAEs}$ in $\mathrm{Fe}_{3} \mathrm{O}_{4}$.

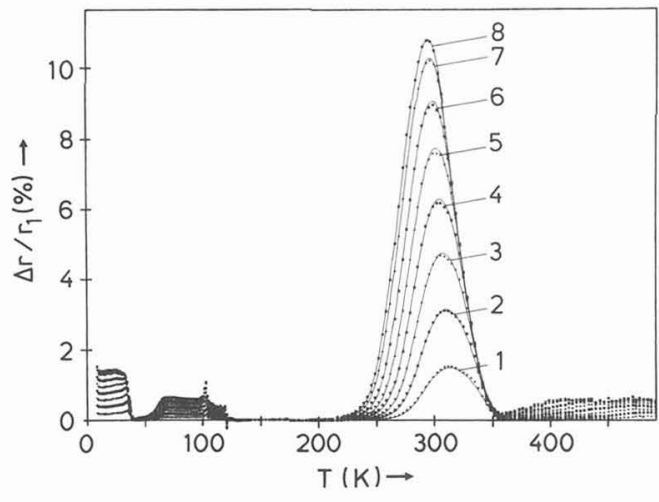

Figure 3: Effect of weak vacancy-doping $\left(\Delta \approx 10^{-4}\right)$ on the MAE spectrum of polycrstalline $\mathrm{Fe}_{3}-\Delta \mathrm{O}_{4}$.

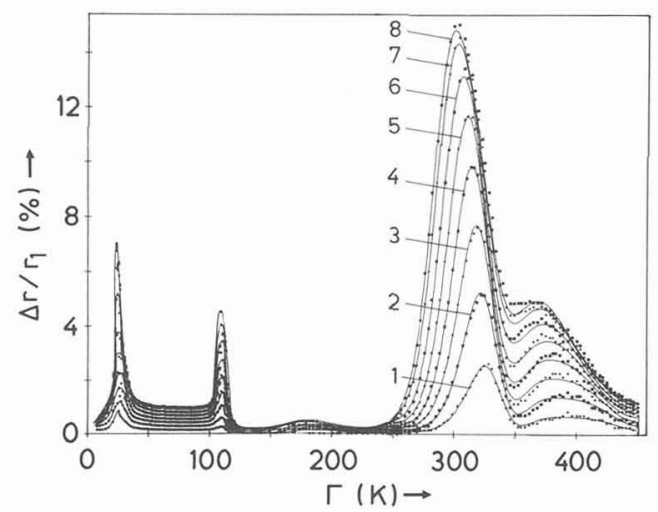

Figure 4: MAE spectrum of weakly doped polycrys-

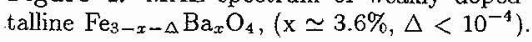




\subsection{Impurity-doped polycrystalline $\mathrm{Fe}_{3-x-\Delta} \mathrm{Me}_{\mathrm{x}} \mathrm{O}_{4}$}

According to the above formula, with $\mathrm{Me}$ and $\Delta$ standing, respectively, for metallic impurities - like $\mathrm{Mn}, \mathrm{Ni}, \mathrm{Zn}$, $\mathrm{Ba}, \mathrm{Ga}$, etc. [6] - and induced vacancy contents, a variety of differently composed spinel ferrites is feasible. Since, a priory, it is open as to what extent and with which valencies potential impurities may be substituted into the tetrahedral (A) or octahedral (B) sublattices of the spinel, the respective MAE spectra - due to correspondingly modified magnetic interactions - are expected to considerably differ from one another. The more it is interesting that, independent of the individual substituent, the following features are common to all spectra of impurity-doped magnetite, as representatively shown in Fig.4 for a Fe $3-x-\Delta \mathrm{Ba}_{x} \mathrm{O}_{4}$ polycrystal $\left(x=3.6 a t \%, \Delta \approx 5 \cdot 10^{-4}\right)$ : With increasing impurity content, $\mathrm{x}$, the low-temperature tunnelling relaxations become completely suppressed, the hopping-plateau severely disturbed - by either elimination or contraction to a peak-like relaxation zone - and the Verwey transition choked down. In the presence of B-site vacancies the corresponding $300 \mathrm{~K}$ process is developped and, quite typically, accompanied by an impurity-induced satellite relaxation near $400 \mathrm{~K}$. Interestingly, this $400 \mathrm{~K}$ relaxation appears also following $\mathrm{e}^{-}$-irradiation (Fig. $2 \mathrm{j}, \mathrm{k}$ ), where it is interpreted as a modified $300 \mathrm{~K}$ process due to interactions with either residual impurities or radiation-induced vacancy clusters. Owing to the specific attributes of $\mathrm{Ba}^{2+}-\mathrm{i}$.e. isotropic $\left({ }^{1} S_{0}\right)$ free ion state, radius $\sim 1.7$ times that of $\mathrm{Fe}^{2+}$ - the hopping zone of this ferrite is shifted to lower temperatures, being escorted by athermal spike-like peaks which are associated with the release of $\mathrm{Ba}^{2+}$-induced sterical stresses at the initiation temperatures of electron-hopping $(30 \mathrm{~K})$ and crystal transformation $(\approx 100 \mathrm{~K})$, Fig.4.

\section{SUMMARY}

The high analytical power of the MAE spectroscopy allowed us to identify all relevant processes in a large number of well-defined $\mathrm{Fe}_{3} \mathrm{O}_{4}$ - based ferrites in the temperature range up to $500 \mathrm{~K}$ [2-6]. As compared to metallic Fe, the ionic structure of ferrites proves to be of decisive advantage for the defect analysis by means of the MAE. Thus, it was a major success to identify the complete defect-genealogy arising in e--irradiated, stoichiometric $\mathrm{Fe}_{3} \mathrm{O}_{4}[5]$. Conversely, in the case of metallic $\alpha$-Fe two irreconciliable recovery mechanisms, the so-called one- and two-interstitial model, are still controversely discussed - although the MAE analyses speak clearly in favour of the latter model [9].

\begin{tabular}{|c|c|c|c|c|}
\hline $\mathrm{T}(\mathrm{K})$ & $\mathrm{H}_{0}(\mathrm{eV})$ & $\tau_{0}(\mathrm{~s})$ & Mechanism & Type \\
\hline $4<T<20$ & $0.03 \pm 0.02$ & $1.0 \cdot 10^{-10 \pm 1}$ & $\mathrm{e}^{-}$-tunnelling & \multirow{5}{*}{ V } \\
\hline 30 & $\begin{array}{l}0.07 \pm 0.01 \\
0.08 \pm 0.01\end{array}$ & $1.0 \cdot 10^{-12 \pm 1}$ & $\begin{array}{l}\mathrm{e}^{-} \text {-tunnelling combined with local excitations, } \\
\text { superposition of } 2 \text { Debye-type processes }\end{array}$ & \\
\hline $50<T<125$ & $0.25 \pm 0.10$ & $1.0 \cdot 10^{-12 \pm 1}$ & Long-range $e^{-h o p p i n g, ~ p r i o r ~ t o ~} e^{-}$-irradiation & \\
\hline 68 & $0.20 \pm 0.05$ & \multirow{2}{*}{$1.0 \cdot 10^{-12 \pm 1}$} & Nearest-neighbour $\mathrm{e}^{-}$-hopping, & \\
\hline 90 & $0.25 \pm 0.05$ & & following $\mathrm{e}^{-}$-irradiation & \\
\hline 160 & $0.55 \pm 0.05$ & $7.0 \cdot \overline{10^{-15 \pm 1}}$ & Reorientation of intrinsic interstitial clusters & \multirow{3}{*}{ IV } \\
\hline 220 & $0.70 \pm 0.05$ & \multirow{2}{*}{$1.0 \cdot 10^{-14 \pm 1}$} & \multirow{2}{*}{ Reorientation of intrinsic interstitials } & \\
\hline 240 & $0.75 \pm 0.05$ & & & \\
\hline \multirow{2}{*}{300} & $0.85 \pm 0.05$ & \multirow{2}{*}{$7.0 \cdot 10^{-15 \pm 1}$} & Reorientation of B-site vacancies, & \multirow{2}{*}{ III } \\
\hline & $0.93 \pm 0.05$ & & superposition of 2 Debye-type processes & \\
\hline 380 & $1.00 \pm 0.05$ & \multirow{2}{*}{$1.0 \cdot 10^{-14 \pm 1}$} & Modified $300 \mathrm{~K}$ process, due to interactions & \multirow{2}{*}{ II } \\
\hline 420 & $1.20 \pm 0.05$ & & with either vacancy clusters or ionc impurities & \\
\hline
\end{tabular}

Table I: Relevant processes occurring in the MAE spectra of $\mathrm{Fe}_{3} \mathrm{O}_{4}$-based ferrites; $\mathrm{T}, \mathrm{H}_{0}, \tau_{0}$ and Type denote the process temperatures, activation enthalpies, atomistic time constants and usual process classification.

\section{References}

[1] Brabers V.A.M., in: Handb. of Magn. Mat., Ed. K.H.Buschow, Vol.8, Ch.3, North-Holland, Amsterdam 1995.

[2] Kronmüller H. and Walz F.,Phil.Mag. B42 (1980) 433-452.

[3] Walz F., Brabers V.A.M., Chikazumi S., Kronmüller H. and Rigo M.O., phys.stat.sol.(a) 110 (1982) $471-478$.

[4] Kronmüller H., Schützenauer R. and Walz F., phys.stat.sol(a) 24 (1974) 487-494.

[5] Walz F. and Kronmüller H., phys.stat.sol.(b) 160 (1990) 661-671; 181 (1994) 485-498.

[6] Walz F., Rivas, J., Martínez, D. and Kronmüller H., phys.stat.sol.(a) 143 (1994) 137-148; 144 (1994) $177-187$.

[7] Walz F., phys.stat.sol.(a) 8 (1971) 125-133; 82 (1984) 179-189; 147 (1995) 237-247; Appl.Phys. 3 (1974) 313-319.

[8] Kronmüller H., Nachwirkung in Ferromagnetika, Springer-Verlag, Berlin/Heidelberg/New York 1968.

[9] Walz F. and Blythe H.J., Cryst.Latt.Def. and Amorph.Mat. 17 (1988) 373-403. 